\title{
AKTIVITAS ANTIBAKTERI EKSTRAK METANOL AKAR TUMBUHAN MERUNG (Coptosapelta tomentosa) TERHADAP BAKTERI Escherichia coli DAN Staphylococcus aureus.
}

\author{
Rullah Hermanda*, Wahyu Widayat, Laode Rijai, \\ Laboratorium Penelitian dan Pengembangan FARMAKA TROPIS, Fakultas \\ Farmasi,Universitas Mulawarman, Samarinda, Kalimantan Timur \\ *email: rullahhermanda@yahoo.com
}

\begin{abstract}
ABSTRAK
Infeksi merupakan penyakit yang disebabkan oleh mikroorganisme prokariotik patogen. Tumbuhan merung (Coptosapelta tomentosa) merupakan tumbuhan yang banyak terdapat di Kabupaten Kutai Kartanegara Kalimantan Timur dengan populasi terbanyak pada terdapat pada kecamatan Tenggarong. Masyarakat Kutai menggunakanakar tumbuhan merung untuk mengobati penyakit infeksi dan penyakit bebrapa degeneratif seperti radang sendi. Penelitian ini bertujuan untuk mengetahui aktivitas antibakteri dari ekstrak metanol akar tumbuhan merung terhadap bakteri gram negatif Escherichia coli dan gram positif Staphylococcus aureus dan mengidentifikasi kandungan metabolit sekundernya. Akar tumbuhan merung diektrasksi menggunakan pelarut metanol dengan metode maserasi kemudian dipekatkan dengan alat rotary evaporator. Identifikasi metabolit sekunder dilakukan secara kualitatif. Aktivitas antibakteri dilakukan menggunakan metode cakram difusi dengan konsentrasi uji $(10,20,100,200,2000,10000) \mu \mathrm{g} /$ disc. Hasil identifikasi golongan metabolit sekunder terdapat senyawa alkaloid, flavanoid, fenol, tanin, dan saponin. Aktivitas antibakteri ekstrak metanol akar tumbuhan merung dimulai pada konsentrasi $100 \mu \mathrm{g} /$ disc.
\end{abstract}

Kata Kunci:, Tumbuhan merung (Coptosapelta tomentosa), metabolit sekunder, antibakteri

\section{PENDAHULUAN}

Tumbuhan Akar Merung (Coptosapelta tomentosa) merupakan tumbuhan yang hidup di daerah hutan hujan tropis, persebaran luasnya hampir di seluruh wilayah Kalimantan. Di daerah Kalimantan Selatan tanaman ini dikenal sebagai manuran. Secara empiris masyarakat Kalimantan selatan menggunakan tumbuhan ini untuk pengobatan secara tradisional untuk pengobatan seperti aprodisiaka, peluruh darah (menstruasi), sedangkan di Kalimantan timur tanaman ini dikenal sebagai merung atau akar merung karena yang digunakan adalah akarnya, masyarakat kutai kartanegara desa Tanjung batu menggunakan atau memanfaatkan akar merung untuk pengobatan radang atau bengkak, reumatik, serta diare. Ciri Tumbuhan merung yaitu tumbuhan dengan arah tumbuh batangnya memanjat dan merupakan jenis batang berkayu, daunnya tipis berwarna hijau jika muda dan berwarna coklat setelah tua, daunnya tipis berwarna hijau berbentuk bulat telur dengan ujung daun yang meruncing. Akar tananaman ini bernentuk tunggang dengan bau akar sangat khas dan menyenga. Tak jarang tanaman ini mirip seperti semak belukar sehingga sulit untuk diketahui. Tumbuhan ini dapat ditemukan di daerah Kalimantan. (Rezeky, 2009).

Menurut laporan WHO penyakit infeksi ini menjadi penyebab kematian terbesar pada anak-anak dan dewasa dengan jumlah kematian lebih dari 13 juta jiwa setiap tahun, menempati urutan kedua (25\%) setelah kardiovaskular (31\%) dari 53,9 juta kasus penyebab 
kematian di dunia dan menjadi penyebab kematian utama pada anak dibawah umur 4 tahun (WHO, 1999).

Infeksi dapat diobati dengan menggunakan antibiotik. Antibiotik adalah senyawa kimia yang dihasilkan oleh fungi dan bakteri tanah, yang memiliki khasiat mematikan atau menghambat pertumbuhan kuman, sedangkan toksisitasnya bagi manusia relatif kecil. Akan tetapi penggunaan antibiotic secara besar-besaran untuk terapi dan profilaksis adalah faktor utama terjadinya resistensi (Tjay et al, 2002).

Oleh karena itu perlu dicari alternatif pengobatan infeksi di samping menggunakan antibiotik yaitu dengan pemanfaatan obat-obat dari bahan alam.

Bakteri Staphylococcus aureus dan Escherichia coli merupakan bakteri pathogen yang sering dijumpai dalam kasus infeksi namun beberapa spesies bakteri tersebut telah banyak yang mengalami resistensi terhadap antibiotik seperti golongan golongan $\beta$-laktam dan golongan aminoglikosida, sehingga perlu dilakukan eksplorasi senyawa kimia yang bersumber dari alam dan hayati merupakan alkternatif untuk menanggulagi permasalahan resistensi antibiotik

Berdasarkan uraian tersebut tujuan penelitian ini adalah mengetahui aktivitas antibakteri dari ekstrak akar tumbuhan merung terhadap serta mengetahui Kadar Hambat Minimum (KHM) dari ekstrak akar tumbuhan merung.

\title{
ALAT DAN BAHAN
}

\begin{abstract}
Alat
Peralatan yang digunakan dalam penelitian ini antara lain peralatan gelas, timbangan analitik, rotary evaporator, desikator, hot plate, tabung reaksi, spatula, pipet tetes, Erlenmeyer, labu takar, tissue, jarum ose, rak tabung reaksi, cawan petri, gunting, aluminium foil, autoklaf, inkubator, lampu spritus, kertas cakram paper disc, kapas, mikropipet, lemari pendingin, Laminar Air Flow (LAF), botol kaca warna coklat, batang pengaduk, mikrometer sekrup, pipet ukur.
\end{abstract}

\section{Bahan}

Bahan uji yang digunakan adalah akar tumbuhan merung yang didapat dari desa Tanjung Batu Kabupaten Kutai Kartanegara Kalimantan Timur. Bakteri uji yang digunakan adalah bakteri Staphylococcus aureus dan Escherichia coli, yang didapat dari Labolatorium Biologi Farmasi Universitas Mulawarman. Bahan-bahan kimia yang digunakan diantaranya: Mueller Hinton Agar (MHA), Nacl 0,9\%, $\mathrm{FeCl}_{3}$, metanol, Serbuk Mg, HCL, Pereaksi dragendorff, pereaksi meyer, kloroform, natrium sulfat anhidrat, asam asetat anhidrat, $\mathrm{H}_{2} \mathrm{SO}_{4}$, aquadest.

\section{METODE PENELITIAN}

\section{Waktu dan Tempat Penelitian}

Penelitian dilaksanakan kurang lebih selama dua bulan, dari bulan September 2016 sampai bulan oktober 2016. Penelitian ini telah dilaksanakan di Laboratorium Penelitian dan Pengembangan FARMAKA TROPIS, Fakultas Farmasi Universitas Mulawarman, Samarinda, Kalimantan Timur. Penelitian dilaksanakan kurang lebih selama dua bulan, dari bulan September 2016 sampai bulan oktober 2016.

\section{Penyiapan Simplisia Akar Merung}

Bahan berupa tumbuhan akar merung (Coptosapelta tomentosa) sebanyak didapat dari desa Tanjung Batu Kabupaten Kutai Kartanegara Kalimantan Timur dalam keadaan 
basah, kemudian dicuci bersih dengan air mengalir, dibersihkan dari tanah, kerikil dan zatzat pengotor lainnya, kemudian dibilas dengan air bersih, jangan dilakukan perendaman yang lama. Akar merung ini kemudian dikeringkan anginkan pada suhu ruang dan terhindar dari sinar matahari langsung. Simplisia kering kemudian dirajang hingga kecil menggunakan pisau atau alat pemotong lainnya. Sehingga diperoleh simplisia kering sebanyak $1,2 \mathrm{~kg}$.

\section{Pembuatan Ekstrak}

Simplisia akar merung (Coptosapelta tomentosa) sebanyak 1,2 kg dimaserasi dengan menggunakan metanol. Simplisia direndam dalam pelarut metanol di dalam alat maserator yang masing-masing berisi $400 \mathrm{~g}$ simplisia akar merung selama dua hari, dengan mengganti pelarut setiap 2 kali 24 jam, kemudian disaring dengan menggunakan kertas saring. Kemudian ekstrak yang diperoleh dipekatkan menggunakan rotary evaporator pada suhu $45^{\circ} \mathrm{C}$, sehingga diperoleh ekstrak kental akar merung. Kemudian ekstrak kental dimasukkan ke dalam wadah kaca dan dikering anginkan.

\section{Pengujian Fitokimia}

\section{Golongan Alkaloid}

Sebanyak $5 \mathrm{ml}$ ekstrak dilarutkan dalam HCL $2 \mathrm{M}$ dan disaring. Filtrat dibagi menjadi dua bagian, dimasukkakn ke dalam tabung reaksi, salah satu bagian ditetesi dengan pereaksi Mayer dan bagian lain ditetesi dengan pereaksi Dragendorff. Pembentukan endapan berwarna putih pada ekstrak yang ditetesi dengan pereaksi Mayer dan pembentukan endapan merah pada ekstrak yang ditetesi dengan pereaksi Dragendorff menunjukkan adanya alkaloid (Tiwari et al, 2011).

\section{Golongan Flavonoid}

Sebanyak $3 \mathrm{ml}$ larutan ekstrak dimasukkan ke dalam tabung reaksi, ditambahkan aquades panas, dididihkan selama 15 menit, ditambahkan serbuk mg secukupnya dan $1 \mathrm{ml}$ HCL pekat dan $1 \mathrm{ml}$ amil alkohol, lalu dikocok dan dibiarkan, jika terbentuk warna jingga atau kuning maka terdapat flavonoid.

\section{Golongan Senyawa Saponin}

Sebanyak 3 ml larutan ekstrak dimasukkan ke dalam tabung reaksi, ditambahkan 1 sampai 2 tetes HCL $1 \%$ lalu dikocok, kemudian didiamkan selama 10 menit, terbentuk busa yang stabil dalam tabung reaksi menunjukkan adanya senyawa golongan saponin.

\section{Golongan Senyawa Tanin}

Sebanyak $3 \mathrm{ml}$ ekstrak dipanaskan dalam tabung reaksi. Dtambahkan beberapa tetes $\mathrm{FeCl}_{3} 1 \%$ dan diamati apabila terbentuk warna hijau kecoklatan atau biru kehitaman maka terdapat senyawa golongan tanin (Ayoola et al, 2008).

\section{Steroid Dan Triterpenoid}

Sebanyak $3 \mathrm{ml}$ ekstrak ditambahkan beberapa tetes kloroform, ditambahkan $\mathrm{H}_{2} \mathrm{SO}_{4}$. Diamati terbentuknya warna coklat kemerahan pada permukaan menunjukkan adanya pada permukaan menunjukkan adanya senyawa golongan steroid dan triterpenoid.

\section{Uji Golongan senyawa Fenol}

Sebanyak $3 \mathrm{ml}$ ekstrak dipanaskan dalam tabung reaksi. Dtambahkan beberapa tetes $\mathrm{FeCl}_{3} 1 \%$ dan diamati apabila terbentuk warna hijau kecoklatan atau biru kehitaman maka terdapat senyawa golongan tanin 


\section{Pengujian Antibakteri}

\section{Sterilisasi Alat dan Bahan}

Sterilisai dilakukan menggunakan autoklaf pada suhu $121^{\circ} \mathrm{C}$ selama $15-20$ menit, semua alat (baik skala maupun tidak). Sebelum melakukan pekerjaan di Laminar Air Flow, LAF disterilisai dengan alkohol $70 \%$ kemudian disterilkan dengan lampu UV yang telah dinyalakan 15 menit sebelum digunakan.

\section{Pembuatan Media}

Media yang digunakan adalah Mueller Hinton Agar (MHA). Media MHA dibuat dengan melarutkan 8,5 g serbuk dalam $250 \mathrm{ml}$ aquades, lalu diaduk-aduk dan dipanaskan hingga bening dan homogeny. Sebelum digunakan media ini disterilkan dalam autoklaf pada suhu $121^{\circ} \mathrm{C}$ selama 20 menit.

\section{Pembuatan Kertas Cakram (paper disc)}

Pembuatan kertas cakram dilakukan dengan menyiapkan potongan kertas saring berdiameter $6 \mathrm{~mm}$ dibuat dari kertas saring Whatman, diletakkan dalam cawan petri kemudian disterilkan dalam autoklaf pada suhu $121^{\circ} \mathrm{C}$ selam 20 menit.

\section{Pembuatan Suspensi Bakteri}

Biakan bakteri yang telah diinkubasi selam 24 jam ditambahkan $9 \mathrm{ml}$ larutan $\mathrm{NaCl}$ 0,9\%, kemudian dibuat larutan suspensi hingga 1:40 di dalam tabung reaksi yang telah disterilkan. Selanjutnya diukur kekeruhannya dengan menggunakan metode turbidimetri dengan standar 0,5 Mc Farland.

\section{Pembuatan larutan uji}

Pada pengujian aktivitas antibakteri menggunakan metode cakram difusi, larutan uji dibuat dengan melarutkan ekstrak metanol tumbuhan akar merung (Coptosapelta tomentosa) menggunakan metanol dengan konsentrasi ekstrak uji yang digunakan $(10,20,100,200$, $2000,10000) \mu \mathrm{g} /$ disc.

\section{Pengujian Aktivitas Antibakteri Ekstrak Akar Tumbuhan Merung}

Pengujian aktivitas antibakteri dari ekstrak metanol akar merung dilakukan dengan metode cakram difusi mengunakan kertas cakram. Kertas cakram yang digunakan memiliki diameter $6 \mathrm{~mm}$.

Medium MHA sebanyak $10 \mathrm{ml}$, dimasukkan ke dalam botol pengencer yang telah disterilkan, kemudian diambil suspensi bakteri 1:40 S. aureus dan E.coli sebanyak $100 \mu 1$ dimasukkan masing-masing kedalam botol pengencer yang sudah berisi medium MHA cair, kemudian dihomogenkan secara vertikal perlahan-lahan. Medium yang berisi suspensi bakteri tadi dimasukkan ke dalam cawan petri dan dibiarkan hingga.

Paper disc yang telah disterilkan kemudian ditetesi dengan larutan uji sebanyak 20 $\mu 1$ kemudian didiamkan hingga kering atau menguap (Rhimou et al, 2010) agar pelarutnya menguap kemudian diletakkan diatas permukaan media agar yang berisi medium dan suspense yang telah memadat tadi di dalam cawan petri. Untuk kontrol negatif kertas cakram ditetesi dengan metanol. Kemudian diinkubasi dalam keadaan posisi terbalik pada suhu $37^{\circ} \mathrm{C}$ selama 24 jam. Aktivitas antibakter. Diamati berdasarkan pengukuran diameter daerah hambat atau daerah bening atau terbentuknya zona bening disekeliling paper disc. Pengujian antibakteri yang telah dilakukan pada bakteri uji, masing-masing dilakukan pada 3 kali pengulangan. 


\section{Analisis Data}

Data analisis digunakan metode Anova satu arah menggunakan SPSS 21 dengan 7 perlakuan (6 perlakuan masing-masing paper disc ditetesi dengan berbagai konsentrasi ekstrak metanol dari akar tumbuhan merung, 1 perlakuan paper disc ditetesi metanol hingga menguap sebagai kontrol negatif), masing-masing perlakuan dilakukan replikasi sebanyak 3 kali. Analisis dilanjutkan dengan Duncan untuk membandingkan daya antibakteri diantara masing-masing perlakuan.

\section{HASIL DAN PEMBAHASAN}

Sampel uji yang digunakan dalam penelitian ini yaitu akar dari tumbuhan merung (Coptosapelta tomentosa) merupakan tumbuhan yang diperoleh dari Kabupaten Kutai Kartanegara Kalimantan Timur dengan populasi terbanyak pada terdapat pada kecamatan Tenggarong.

Metode ekstraksi yang digunakan dalam penelitian ini adalah metode maserasi. Metode ini dipilih karena proses pengerjaannya yang mudah, peralatan yang digunakan sederhana, serta tidak merusak senyawa yang terkandung dalam sampel uji. Prinsip dari metode maserasi adalah mengekstrak zat aktif dengan cara merendam sampel simplisia kering dalam larutan penyari yang sesuai pada suhu kamar. Pelarut yang digunakan dalam proses maserasi ini adalah metanol sebagai pelarut dikarenakan metanol merupakan pelarut polar, pelarut polar memiliki kelebihan dalam mengekstraksi komponen senyawa pada ekstrak, dapat melarutkan hampir semua metabolit sekunder yang ada pada sampel uji, baik senyawa yang bersifat polar ataupun nonpolar sehingga proses pengekstrakan dapat dilakukan dengan optimal.

Ekstrak akar merung yang diperoleh selanjutnya diidentifikasi kandungan metabolit sekunder secara kualitatif. dapat dilihat pada Gambar 1 dan Tabel 1.

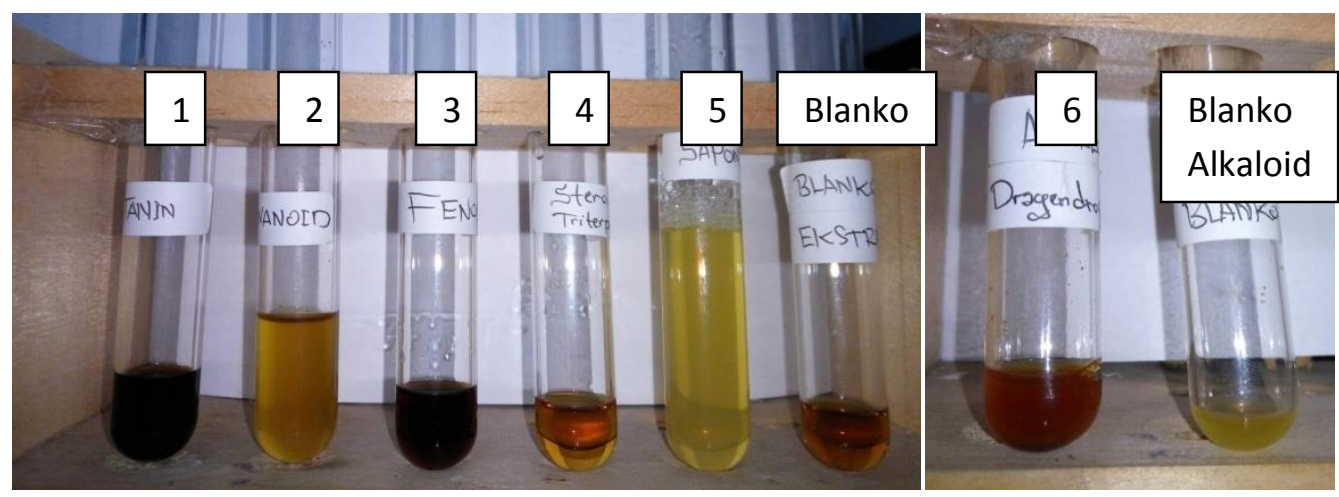

Gambar 1. Uji metabolit sekunder secara kualitatif

Tabel 1. Hasil Pengamatan Uji metabolit sekunder

\begin{tabular}{llcl}
\hline No & Golongan Metabolit Sekunder & Hasil & \multicolumn{1}{c}{ Keterangan } \\
\hline 1 & Tanin & + & berwarna hitam kemerahan \\
2 & Flavanoid & + & berwarna warna jingga \\
3 & Fenol & + & Terbentuk warna hitam Kecoklatan \\
4 & Steroid/Triterpenoid & - & - \\
5 & Glikosida & + & Terbentuk buih setinggi $1 \mathrm{~cm}$ \\
6 & Alkaloid & + & $\begin{array}{l}\text { Ditambahkan pereaksi dragendroff terbentuk } \\
\text { endapan coklat }\end{array}$ \\
\hline
\end{tabular}


Berdasarkan Hasil pengujian fitokimia yang dilakukan menunjukkan bahwa sampel uji ekstak metanol akar merung, diduga memiliki kandungan kimia dari golongan senyawa alkaloid, flavanoid, fenol, tanin, dan saponin.

Metode uji aktivitas antibakteri yang digunakan adalah metode cakram difusi. Kontrol negatif yang digunakan dalam penelitian ini adalah pelarut metanol yang diteteskan pada paper disc dan ditunggu hingga menguap hingga kering. Kontrol negatif yang digunakan adalah metanol. Metanol merupakan pelarut yang digunakan sebagai pelarut untuk membuat seri konsentrasi dari ekstrak untuk mengetahui apakah zona bening yang dihasilkan juga dipengaruhi oleh metanol. Tujuannya adalah sebagai pembanding bahwa pelarut yang digunakan sebagai pengencer tidak mempengaruhi hasil uji antibakteri ekstrak. Hasil zona hambat kontrol negatif terhadap kedua bakteri uji adalah $0 \mathrm{~mm}$. Pelarut metanol tidak mempengaruhi aktivitas dalam meghambat pertumbuhan bakteri ditandai dengan tidak terbentuknya zona bening sehingga dapat disimpulkan metanol tidak mempengaruhi aktivitas antibakteri dari ekstrak. Konsentrasi ekstrak yang digunakan pada pengujian yaitu $(10,20,100,200,2000,10000) \mu \mathrm{g} /$ disc masing-masing konsentrasi dalam $20 \mu \mathrm{l}$ lalu diteteskan pada paper disc menggunakan mikrometer lalu didiamkan hingga pelarut menguap. Selanjutnya diletakkan perlahan pada medium, berisi suspensi bakteri yang telah memadat di cawan petri. Diinkubasi pada suhu $37^{\circ} \mathrm{C}$ selama 24 jam.

Hasil pengujian aktivitas antibakteri ekstrak metanol akar tumbuhan merung (Coptosapelta tomentosa) terhadap bakteri Staphylococcus aureus dan Escherchia coli menunjukkan adanya aktivitas penghambatan dan pembunuhan pertumbuhan bakteri uji. Hal ini dapat dilihat dari hasil pengujian yang dilakukan yaitu wilayah bening disekeliling kertas cakram yang mengandung ekstrak akar merung yang dapat dilihat pada Gambar 2.
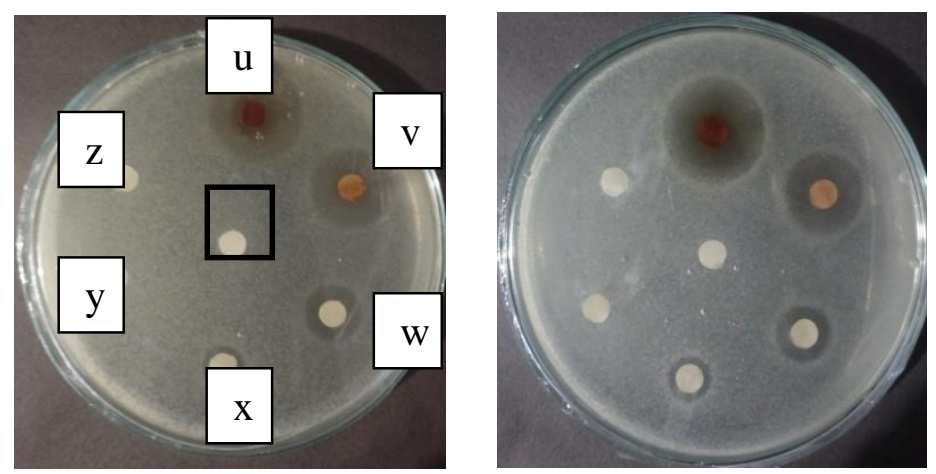

Gambar 2, Pengujian Antibakteri Terhadap Bakteri Escherichia coli dan Staphylococcus aureus

Keterangan, konsentrasi bobot ekstrak pada paper disc :

$\begin{array}{ll}\square=\text { Kontrol negatif metanol } \\ u .10000 \mu \mathrm{g} & \text { x. } 100 \mu \mathrm{g} \\ v .2000 \mu \mathrm{g} & y .20 \mu \mathrm{g} \\ w .200 \mu \mathrm{g} & \text { z. } 10 \mu \mathrm{g}\end{array}$

Masing-masing pengujian dilakukan sebanyak tiga replikasi dari masing-masing bakteri yang digunakan. Hasil rata-rata pengukuran diameter zona hambat atau bening masing-masing konsentrasi pada setiap replikasi ekstrak metanol akar tumbuhan merung 
terhadap bakteri Escherichia coli dan Staphylococcus aureus dapat dilihat masing-masing pada Tabel 2.dan Tabel 3.

Tabel 2. Hasil rata-rata pengukuran zona hambat atau bening ekstrak metanol akar tumbuhan merung terhadap bakteri Escherichia coli.

\begin{tabular}{lcccc}
\hline \multirow{2}{*}{$\begin{array}{l}\text { Konsentrasi Ekstrak } \\
\text { Per paper disk }\end{array}$} & \multicolumn{2}{c}{$d$ zona bening per paper disc $(\mathrm{mm})$} & Rata-rata \\
\cline { 2 - 4 } Kontrol negatif & E. coli I & E. coli II & E. coli III & $(\mathrm{mm})$ \\
$10 \mu \mathrm{g}$ & 0 & 0 & 0 & 0 \\
$20 \mu \mathrm{g}$ & 0 & 0 & 0 & 0 \\
$100 \mu \mathrm{g}$ & 0 & 0 & 0 & 0 \\
$200 \mu \mathrm{g}$ & 7,74 & 10,72 & 8,71 & 9,06 \\
$2000 \mu \mathrm{g}$ & 11,05 & 11,44 & 11,58 & 11,36 \\
$10000 \mu \mathrm{g}$ & 13,89 & 15,59 & 16,80 & 15,43 \\
& 17,18 & 19,32 & 20,69 & 19,06 \\
\hline
\end{tabular}

Tabel 3. Hasil rata-rata pengukuran zona hambat atau bening ekstrak metanol akar tumbuhan merung terhadap bakteri Staphylococcus aureus

\begin{tabular}{|c|c|c|c|c|}
\hline \multirow{2}{*}{$\begin{array}{l}\text { Konsentrasi Ekstrak } \\
\text { Per paper disk }\end{array}$} & \multicolumn{3}{|c|}{$d$ zona bening per paper disc (mm) } & \multirow{2}{*}{$\begin{array}{c}\text { Rata-rata } \\
(\mathrm{mm})\end{array}$} \\
\hline & S. aureus I & S. aureus II & S. aureus III & \\
\hline Kontrol negatif & 0 & 0 & 0 & 0 \\
\hline $10 \mu \mathrm{g}$ & 0 & 0 & 0 & 0 \\
\hline $20 \mu \mathrm{g}$ & 0 & 0 & 0 & 0 \\
\hline $100 \mu \mathrm{g}$ & 9,38 & 9,28 & 10,01 & 9,55 \\
\hline $200 \mu \mathrm{g}$ & 11,21 & 10,33 & 11,30 & 10,94 \\
\hline $2000 \mu \mathrm{g}$ & 15,06 & 16,97 & 16,64 & 16,22 \\
\hline $10000 \mu \mathrm{g}$ & 19,35 & 20,01 & 20,73 & 20,03 \\
\hline
\end{tabular}

Berdasarkan data di atas dapat dilihat perbandingan diameter hambat rata-rata ekstrak metanol akar merung terhadap bakteri $E$. coli dan $S$. aureus pada gambar 3 .

Dapat dilihat pada tabel 2 dan tabel 3 dan kurva diatas hasil uji aktivitas antibakteri pada penelitian ini dapat dilihat bahwa ekstrak metanol akar tumbuhan merung (Coptosapelta tomentosa) memiliki aktivitas antibakteri terhadap 2 bakteri uji yang digunakan yaitu bakteri gram negatif Escherichia coli dan bakteri gram positif Staphylococcus aureus. Hal ini dapat dilihat dari terbentuknya zona hambat pada medium agar dengan berbagai konsentrasi yang digunakan yakni zona hambat dimulai dari konsentrasi $100 \mu \mathrm{g}, 200 \mu \mathrm{g}, 2000 \mu \mathrm{g}$, dan $10000 \mu \mathrm{g}$. sedangkan pada konsentrasi $10 \mu \mathrm{g}$ dan $20 \mu \mathrm{g}$ tidak terdapat aktivitas antibakteri karena tidak terbentuk zona hambat. Dilihat dari kurva diatas konsentrasi paling tinggi dalam menghambat pertumbuhan bakteri adalah $10000 \mu \mathrm{g}$. 


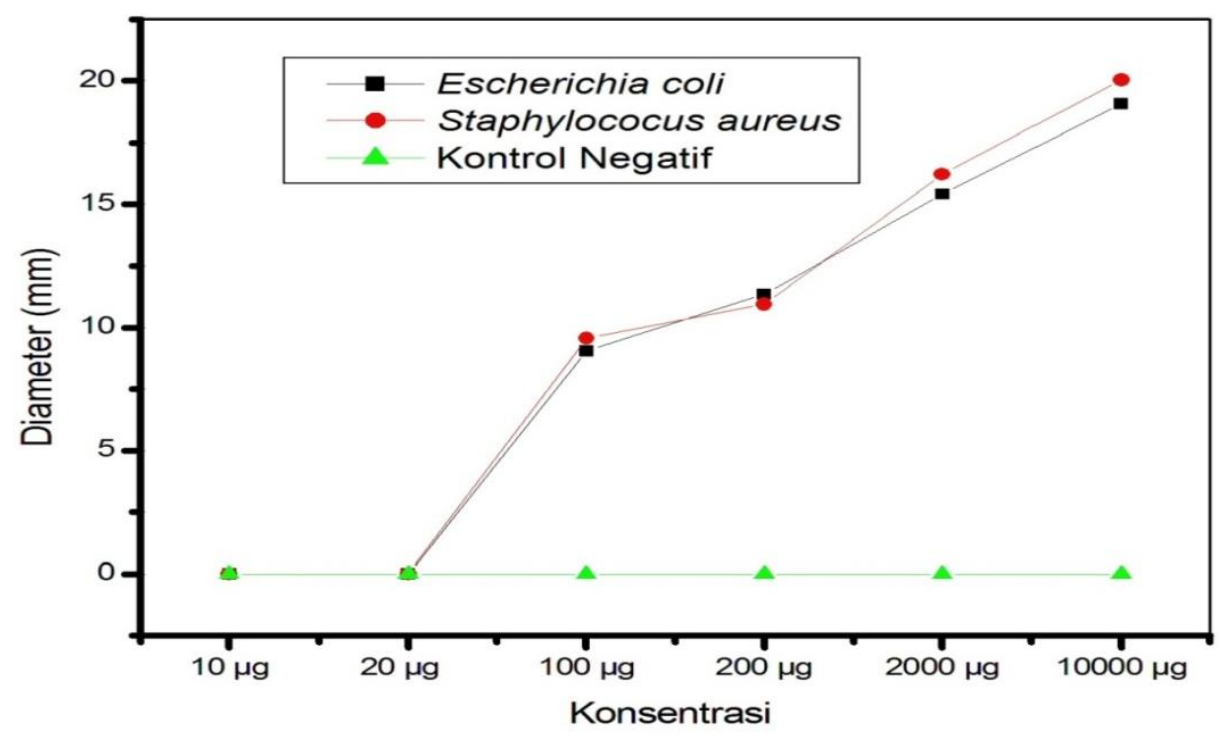

Gambar 3. Kurva perbandingan diameter hambat rata-rata ekstrak metanol akar merung terhadap bakteri E. coli dan S. aureus

Hasil analisis data menggunakan SPPS 21 bahwa ekstrak metanol akar merung (Coptosapelta tomentosa) mempunyai aktivitas yang berbeda nyata $\mathrm{P}<0,05$ dalam menghambat pertumbuhan bakteri Escherichia coli dan Staphylococcus aureus.

Aktivitas antibakteri dari ekstrak tanaman kemungkinan disebabkan oleh adanya senyawa tanin dan flavonoid yang berikatan dengan dinding sel bakteri dan menghambat proses biosintesisnya.

\section{KESIMPULAN}

Berdasarkan hasil penelitian uji antibakteri dari ekstrak metanol akar merung dapat disimpulkan bahwa ekstrak metanol akar tumbuhan merung memiliki aktivitas antibakteri terhadap bakteri uji Escherichia coli dn Staphylococcus aureus dimulai dari konsentrasi 100 $\mu \mathrm{g}, 200 \mu \mathrm{g}, 2000 \mu \mathrm{g}$ dan yang paling aktif dalam menghambat pertumbuhan bakteri paling besar pada masing-masing bakteri uji ada pada konsentrasi $10000 \mu \mathrm{g}$. sedangkan nilai KHM (Konsentrasi Hambat Minimum) ada pada konsentrasi $100 \mu \mathrm{g}$.

\section{DAFTAR PUSTAKA}

Rezeky, F.C. 2009. Aktivitas Afrodisiaka Ekstrak Metanol Akar Manuran Pada Mencit Putih Jantan. Skripsi Fakultas MIPA UNLAM. Banjarbaru.

WHO. 1999. Infectious Diseases are the Biggest Killer of the Young. Diakses tanggal 20 oktober 2016. Dari http://www.who.int/infectious-disease-report/index-rpt99.htm.

Jawetz, Ernest. 1996. Mikrobiologi Kedokteran edisi 20. EGC : Jakarta.

Tjay T. H. Dn R. Kirana. 2002. Obat-Obat Penting, ed 5, PT. Elex Media Komputindo, Jakarta.

Tiwari, Phrasant., Bimlesh Kumar., Mandeep Kaur., Gurpreet Kaur., Harleen Kaur. Phytochemical Screening and Extraction : A Review. Internationale Pharmaceutica Sciencia Jan-March 2011, vol 1, issue 1.

Ayoola, GA., dkk. 2008. Phytochemical screening and Antioxidant Activities of Some Selected Medicinal Plants Used for Malaria Therapy in Southwestern Nigeria. Tropical Journal of Pharmaceutical Research, September 2008; 7(3): 1019-1024. 